POLSKA AKADEMIA UMIEJĘTNOŚCI

TOM XIII

KULTURA SŁOWIAN. ROCZNIK KOMISJI KULTURY SŁOWIAN PAU

2017

DOI 10.4467/25439561KSR.17.009.7879

ANNA RAŹNY

Ignatianum

Kraków

\title{
ХРИСТИАНСКИЕ ЦЕННОСТИ КАК ОСНОВА ПОЛЬСКО-РОССИЙСКОГО ДИАЛОГА
}

\author{
CHRISTIAN VALUES AS THE BASE \\ OF POLISH-RUSSIAN COMMUNICATION
}

\begin{abstract}
Streszczenie
Odmienne ukształtowanie cywilizacyjne Polski i Rosji stało się przedmiotem wielu opracowań. Mają one głównie charakter historyczny i sytuują się w obrębie historii politycznej oraz historii idei, bądź charakter kulturowy i wchodzą w obręb historii kultury czy historii literatury. Dominująca jest tendencja historyczna, która eksponuje ideowo-polityczny wymiar stosunków polsko-rosyjskich w kontekście religijnym. Zarówno w pierwszym, jak i drugim przypadku wykładnia antropologiczna traktowana jest marginalnie. Wykorzystanie jej sprowadza się do wskazania na opozycję między wyznacznikami cywilizacji łacińskiej - personalizmem i indywidualizmem - przenikającymi polonizm, a wspólnotowością prawosławia jako rosyjskiej „stałej danej”, determinanty cywilizacyjnej. Głębsze spojrzenie na różnice antagonizujące stosunki polsko-rosyjskie pozwala dostrzec płaszczyznę dialogu i spotkania, rysującą się w wymiarze antropologiczno-aksjologicznym. Jest to wymiar wartości chrześcijańskich wspólny dla ukształtowania cywilizacyjnego zarówno Polski, jak i Rosji. Na ich fundamencie możliwe jest budowanie płaszczyzny spotkania i dialogu $-\mathrm{z}$ poszanowaniem odrębności politycznej i cywilizacyjnej.
\end{abstract}

\section{Summary}

After the fall of communism and the collapse of the USSR, a new phase of Polish-Russian relations began. Rather than being bound by the ideals of a compromised communism, the two countries began to shape new, necessary relations based on universal values belonging 
to the spheres of civilization, politics, culture, and social life. These new ideas were a part of Christianity, whose foundation was based on human rights, and likewise the communication of partnered sovereign states. This is a realistic perspective of Polish-Russian relationships, where Poland respects these values, while Russia returns to them.

Słow k klucze: chrześcijańskie wartości, prawda historyczna, relacje polsko-rosyjskie, dialog Key words: Poland, Russia, Christian values, dialogue

После круглого стола в Польше в 1989 году и наступивших после него, так называемыемых, свободных выборах началась новая эпоха в польско-российских отношениях. Её укрепили: крушение коммунизма и распад Советского Союза. Утверждаемое во время «реального социализма» искусственное единство «стран народной демократии» рухнуло в прах. Этот переломный момент показал польскому и российскому обществу, что основанные на фальшивой идеологии: единство, единомыслие, дружба народов имеют иллюзорный характер. Однако осознание этой правды не привело ни в Польше ни в России к преодолению взаимонепонимания в прошлом и настоящем, главным образом на межнациональном и межгосударственном уровнях. Надо подчеркнуть, что в межличностных польско-российских отношениях это взаимонепонимание имело всегда настолько меньший обём, что возможные в них были: взаимопонимание и искренняя благожелательность. Естественно, что в этой сфере осуществляемый даже в советское время обмен мнениями и утверждаемая человеческая солидарность нашли после 1991 года шанс более официального развития, но одновременно не подчиненного преходящим лозунгам и требованиям политики. С другой стороны на официальном, межнациональном, государственно-политическом уровне польско-рсссийских отношений появился шанс преодоления искусственных барьеров националистических, конфесиональных, культурных. Появилась возможность осознания и преодоления мессианских и утопических мифов, которые веками использовала идеология на почве политики обоих государств.

Большинство польского и российского общества поняло, что на фальши невозможно развивать взаимоотношения. Правда стала ценностью детерминирующую все их сферы. Наряду с ней ключевыми стали для обеих наций христианские ценности как основа их цивилизационного будущего.

До возникновения в первой половине XX века теории ценностей - благодаря работам Макса Шелера, Рудольфа Лотце, Эдмунда Гуссерля и других философов, занимающихся проблемой значимости обьекта в отношении к целям, стремлениям и потребностям человека - христианские ценности обозначали огромный духовный опыт опирающийся на евангельские заповеди. Его наиболее убедительным свидетельством являются - с самого начала до сих пор - философия, главным образом онтология, аксиология и этика, модель общества, култура 
и политика. Все они создали определенный статус человека, общества и народа, а также формулу их поведения, называемую часто христианской цивилизацией, Uniwersum Christianum. В Uniwersum Christianum - согласно концепции цивилизации Арнольда Тойнби - цивилизационной силой и мировоззренческой основой являются христианские ценности. Благодаря им христианство является универсальной религией превысшающей не только языческие верования, но и другие религии. По мнению Тойнби цивилизация не имеет ни биологического, ни географического характера - что подчеркивал Оскар Шпенглер в Закате Европь. В своей работе Постижение истории ${ }^{l 1}$ - Тойнби пишет, что цивилизация является свидетельством стремления каждого человека и всего человечества к самоопределению детерминированному в области сознания, свободы и воли. В этом стремлении религия играет самую важную роль ${ }^{22}$.

С точки зрения теории Кристофера Доусона, представляющей религию как источник культуры и стимул её развития, христианские ценности являются гарантией её жизненности. Следует добавить, что по мнению Доусона культура не может сохранять своё существование без религии и что единственный выход из духовного кризиса в каждой эпохе заключается в обращении к этому неизменяемому, вечному источнику культурного творчества. В книге Религия и культура Доусон пишет, что во всех эпохах развития человечества религия была силой объединяющей людей. Без религии нельзя понять внутренней формы общества, его истории и культурных достижений. «Храмы богов - резюмирует Доусон - это самое прочное творение человеческих рук» ${ }^{33}$. В формировании западной цивилизации, отождествляемой Доусоном с Европой, христианство стало главной оформляющей ее религией. Подобно выглядит связь религии с культурой в области византийской цивилизации, которой Россия стала самым важным наследником.

Здесь надо подчеркнуть, что некоторые теоретики - нп. польский ученый Феликс Конэчны и его ученики - выделяют в т.н. христианской цивилизации две разновидности: латинскую и византийскую. В обеих разновидностях фундаментом морали и общественной жизни является христианская этика, благодаря которой возникли христианские ценности. Без этой этики невозможным стало бы сформирование упомянутых разновидностей христианской цивилизации.

1 А. Тойнбии, Постижение истории, пер. Е. Д. Жаркова, Москва 2001.

2 Cp.: P. Skudrzyk, Losy cywilizacji wedlug Arnolda Toynbeego, Katowice 1992.

${ }^{3}$ Ch. Dawson, Religia i kultura, tłum. J. W. Zielińska, Warszawa 1959, с. 58, пер. А. Р. Cp: J. Oesterle, Etyka, tłum. J. Sulowski, Warszawa 1965; J. de Finance, Ethique generale, Rome 1967; P. Jaroszyński, Dramat życia moralnego, Mikołów 1992; F. Ricken, Etyka ogólna, tłum. P. Domański, Kęty 2001; T. Ślipko, Zarys etyki ogólnej, Kraków 2004, wyd. IV; P. Kaźmierczak, Dietrich von Hildebrand wobec narodowego socjalizmu, Kraków 2011. Vide: F. Koneczny, Obronić cywilizację tacińska, Lublin 2002; F. Koneczny, O ład w historii, Kraków 2003. 
Они отличаются уникальным онтологическим, эпистемологическим и аксиологическим сформированием, в котором самую важную роль играют такие философские, этические, общественные ценности как, с одной стороны - свобода и ответственность личности, моральная ответственность, персонализм (на византийской почве - соборный персонализм) и солидаризм - с другой равенство людей и принцип общего блага (bonum commune), которого полную концепцию предложил святой Фома. Они воспринимаются как христианские ценности, направляющие бытие как отдельного человека, так и общества и одновременно народа к Трансценденции. Благодаря им - подчеркивают представители антропологического персонализма всех ветвей, в том числе французской (Франсуа Мунье, Габриель Марсель, Поль Рикэр, Морис Недонсель) и польской (Кароль Войтыла, Йосиф Тишнер) возникла Всеобщая декларащия прав человека, принята резолюцией 217 Генеральной Ассамблеи ООН 10 декабря 1948 года. Ее три первые статьи вытекают непосредственно из таких христианских ценностей как: персонализм, свобода человека и его ответственность, принцип братства и солидаризма, bonum соттипе, личная неприкосновенность» ${ }^{44}$. Целая Декларация обоснована на христианских ценностях - доказывает Мечыслав Кромпец, представитель польского неотомизма, исходящего из учения Фомы Аквинско$\mathrm{ro}^{55}$. Польский философ подчеркивает приоритет прав человека над суверенитетом государства и народа. Этот приоритет основан не только на христианских ценностях. Кроме них его фундаментом являются: христианский персонализм, христианская этика и, сформулированная Фомой Аквинским, концепция общего блага. Все они вместе стали опреденляющим фактором чувства достоинства и свободы личности, ее собственной онтологической и моральной ответственности. Если говорить о причинах возникновения Декларащии и ее характере пишет Кромпец - надо обратить внимание на Преамбулу, в которой выражается дух персонализма ведущий к диалогической форме межличностных и межнациональных связей. Она указывает на диалогическое направление не только между отдельными личностями, но и народами. Можно сказать, что человек является ee dramatis persona. В Декларации, фундирующей диалог как основную форму межличностной и межнациональной коммуникации, видна значимая акцентировка неповторимости и максимальной ценности личности как таковой. Как подчеркивает А. Кромпец такая концепция человека заложена не только антифизикалистскими и антинатуралистическими его интерпретациями, но и идеями трансцендентности целей его существования ${ }^{67}$. По его мнению в Декларации инспирируемой философским христианским персонализмом понятие демокра-

${ }^{4}$ Всеобщая декларация прав человека, http://www.un.org/ru/documents/decl conv/declarations/ declhr.shtml, 2012-09-23, с. 1, дост. 19.09.2017.

${ }_{5}$ M. Krąpiec, Prawa czlowieka, [в:] tegoż, O ludzka politykę. Dzieła, t. XVII, Lublin 1998.

${ }^{6}$ M. Krąpiec, Człowiek jako osoba, Lublin 2005, c. 114-145. 
тии не могло получить этически нейтрального значения ${ }^{78}$. Оно детерминировано тезисом о неповторимости личности и высшей сущности ее свободы. Такое направление Декларации повлияло на вытекающее из нее международное право, объектом которого является человеческая личность, а также создаваемые ею: нация и общество. Из христианского персонализма и концепции человеческого достоинства как самой главной христианской ценности вытекают следующие атрибуты Декларащии, главным образом свобода, равенство и справедливость. Именно Декларация показывает, что христианские ценности всегда выступают вместе. Ими нельзя руководиться поодиночке, нельзя выбирать среди них конкретные определенные, потому что они вместе - как подчеркивает польский аксиолог Владислав Стружэвски - создают фундамент т.н. интегральной морали, противоположной селективной и аскетеческой морали ${ }^{89}$. Совокупность христианских ценностей образует принцип абсолютного императива, чуждого не только язычеству, но и иным, так называемым, мировым религиям. Это принцип любви - гарантия не только персонализма, свободы, солидарности, равенства, общего блага, но и самой человеческой личности. Практическое воплощение этого принципа проявляется в межличностных связях, детерминирующих межнациональные и межобщественные формы отношения и коммуникации. Одной из них является диалог, осуществляемый вне философии диалога, которая является лишь его вербальной концепцией.

Современные теории цивилизации игнорируют религиозный и связанный с ним этический её компонент. Причиной того является новая идеологизация науки и её подчинение политической корректности - с одной стороны, с другой - диктатура релятивизма, как называет уход от ценностей в культуре, науке и политике итальянский профессор, Роберто де Маттеи в книге La dittatura del relativismo ${ }^{9}$. Они формируют модель новой, глобальной цивилизации - атеистической, направленной против христианских ценностей, имеющих универсальный характер. В связи с этим цивилизацию сформированную на основе хриситанской этики лучше определить как динамический процесс осуществления ее ценностей - их осознания, усвоения и реализации. На уровне современных концепций христианские ценности чаще всего выступают в роли стандартов человеческого поведения обусловленного одними и теми же обстоятельствами. Это путь их политической нейтрализации, потому что понятие стандарта, которое не получает значения ни онтологического, ни аксиологического термина, не обладает конкретным семантическим смыслом. В последнее время даже из них вытесняется христианский фактор, который изгоняется из западной цивилиза-

${ }^{7}$ M. Krąpiec, Prawa człowieka, op. cit., c. 187-242.

${ }^{8}$ W. Stróżewski, Istnienie i wartość, Kraków 1981, c. 217-309.

9 R. de Mattei, La dittatura del relativismo, Rzym 2003 ; пер.на польский язык: R. De Mattei, Dyktatura relatywizmu, Kraków 2009. 
ции на уровне - прежде всего - идей и понятий. Таким образом уничтожается её генетический код, её имманентные христианские атрибуты. В последствии этого процесса сам человек теряет свое онтологическое значение как субъект христианских ценностей, определяемый персонализмом творческой творящей личностью, которая реализует коммуникативные ценности путем диалога. Таким образом - как подчеркивает М. Кромпец - личность может быть противопоставлена анонимному обществу, в котором демократия может оказаться формой тирании над ней ${ }^{10}$. В настояящее время это является свидетельством кризиса цивилизации - её болезни. Самые христианские ценности не болеют, потому что они - как утверждал Макс Шелер - априорны и объективны. Болеют идеологии и фундированная ими политика, примером чего является Еввропейский Союз, к которому присоединилась Польша.

Польский круглый стол не был началом декоммунизации, а лишь попыткой примирения коммунистов с т.н. демократической оппозицией и кончился договором между ними, в результате которого началась эпоха посткоммунизма, принимающего влияния Запада во всех сферах жизни. В общественной и культурной они получили отрицательный характер, который вытекает из либеральной философии человека (главным образом свободы), идеологии политической корректности и культуры постмодернизма-гендеризма с их антиаксиологическими императивами. Все они явно стали выступать против христианских ценностей, которые легли у основ не только польской и западно-европейской культурной традиции, но и русской.

Став членом Европейского союза, а затем приняв Лиссабонский договор, Польша официально подчинилась на уровне права влияниям западной культуры, отрицающей христианское наследие Европы и одновременно утверждающей негативную концепцию свободы и несвободы от чего-либо. Впервые правовой основой борьбы с христианскими ценностями стала конституция - принятый всеми членами Европейского союза т.н. Лиссабонский договор, отвергающий ссылку на Бога и христианское наследие Европы. Непосредственно он не касается России, однако оказывает влияние на отношения Евросоюза с ней.

В настоящее время в Польше борьбу за христианские ценности может возоглавлять, связанный с ними, классический консерватизм, выступающий против постмодернизма-гендеризма и идеи стирания западным глобализмом национально-территориальных границ во имя наднационального и надцивилизационного политического и экономического объединения. Важной предпосылкой польско-русского диалога является феномен консерватизма в современной России, выступающий рядом с ее триумфальным возвратом к христианству и национальной традиции. Это феномен проявляющийся в эпоху постхристианского

${ }^{10}$ M. Krąpiec, Prawa człowieka, op. cit., c. 187-242. 
Запада - постхристианской Европы, которой угрожает цивилизация фундаментального ислама. Фактов и аргументов, которые дают возможность правильно судить о связях русского консерватизма с христианством довольно много. Они имеют разнообразный характер. На первый план выдвигаются чисто религиозные и аксиологические связи с христианскими ценностями, обнимающими человека, народ, общество. Именно эти связи имеют атрибуты постоянных данных, констант, детерминирующих современный русский консерватизм, позволяющих определить его идейную автономию и идентичность. Они представляют возможность и надежду вполне ответственно говорить о польско-российском диалоге на почве христиаиских ценностей и современного консерватизма..

Согласно учению Жозефа де Местра классический консерватизм ${ }^{11}$ - подобно христианству - относится к обществу как к организму. Общественный организм складывается из множества судеб и институтов, зависимых друг от друга, опирающихся на определённую традицию и обычаи. Его нельзя механически изменять, не обращая внимания на его специфику, так духовную, как и материальную. Его нельзя также сконструировать, потому что он развивается в результате эволюции всей системы собственных инситутов, которые не могут быть заимствованы извне.

Основу классического консерватизма образует идея коллективной стратегии спасения, согласно которой путь к духовному совершенствованию это участие в создании общего дела, защита общей земли, общей культуры и традиции. Стратегия общего спасения, о которой говорят с одной стороны русские славянофилы и их современные последователи, с другой - польские романтики и их поклонники в XX веке, отличает эти два консерватизма от консерватизма англосаксонского с его апологией индивидуализма и установкой на защиту частной собственности от посягательств со стороны государственной власти. Коллективная установка отличает польский и русский консерватизм и от современной европейской версии консерватизма, т.е. идеологии «новых правых», тяготеющей к дохристианской, языческой традиции, и от американского неоконсерватизма, т. н. неоконы.

Вырастающее из христианской традиции духовное и моральное соучастие обеспечивает развитие традиции классического консерватизма в настоящее время. Очевидно, они выступают как константы сопутствующие христианской

11 Эдмунд Берк первым выступил с радикальной критикой французской революции как стихии уничтожающей традицию и высокие ценности - духовные, религиозные и этические - формирующие столетиями культурный и моральный фундамент каждого народа. Его Размышиления о револющии во Франции, опубликованные в 1790 г., это памфлет против революционного насилия и одновременно апофеоз естественногоо, т.е. мирного исторического развития. Жозеф де Местр в изданной в 1796 г., работе Рассуждения о Франщии, допускает революционный процесс лишь как божественный замысел, целью которого было очищение Франции от зла просвещения. 
религиозной традиции и христианским етическим принципам. Христианское соучастие и солидаризм это важнейшие признаки классического консерватизма в современном мире. Однако это не означает согласия с распространяемым американскими неоконсерваторами глобализмом и его идеей стирания национально-территориальных границ во имя наднационального и надцивилизационного политического и экономического объединения.

Одновременно выступающие в работах таких авторов как Плинио Корреа де Оливейра, Андреа Маттеи, Никола Гомез Давилла - традиции классического консерватизма заставляют его современных представителей отказаться от социал-демократических лозунгов социального и экономического равенства всех членов общества. Согласно пастырской конституции Второго Ватиканского собора Gaudium et spes равенство людей заключается в призвании каждого человека к полноте жизни, которая на много превышает размеры его земного существования. Именно по этой причине католическая Церковь выступает против расизма и других форм дискриминации, соединяя идею сообщества и солидаризма с персонализмом, на почве которого развилась идея защиты прав человека. Связанный с католическим учением классический консерватизм разделяет с ним вытекающий из персонализма взгляд на человека и общество, провозглашая духовное и онтическое равенство всех людей. Выступает против либеральной концепции элиты, играющей роль творческого, привилигированноого меньшинства, освобождённоого от всякой ответственности перед общественным большинством - экономическими и культурными низами. Согласно католическому социальному учению, народ, общество рассматриваются им как одна семья, о которой заботятся все но, обязательно, государственные органы. О сограждан они должны заботиться как о членах семьи, а не сотрудниках бизнес-корпорации. Власти должны способствовать свободе, экономическому благополучию, духовному развитию и обеспечению достойного уровня жизни граждан.

То же самое утверждает Русская Православная Церковь и современный русский консерватизм, пример которого дал в своих работах Александр Панарин. Христианство согласно выдвигает перед обществом и его властью задачу создания предварительных условий для творческого, духовного самосовершенствования всех членов общества. Согласно отвергает всевласть законов рынка над обществом. Рынок должен восприниматься как инструмент реализации определённых общественных потребностей. Католическое социальное учение, вдохновляющее многих современных консерватистов, считает естественными требованиями лозунги обязательности доступного образования и здравохранения, а также обеспечение прожиточного минимума для выживания малоимущих. Католическая социальная доктрина, которой характер определил Папа Лев XIII в энциклике Rerum Novarum от 1891 года, подчёркивает личную ответственность христиан за распространение несправедливости в мире. Это высокая ответст- 
венность, которая никогда не исчезает. В новых - политических, экономических и общественных - условиях жизни, которые появились в XX веке, она принимает роль константы позволяющей определить идентичность не только католической доктрины, но и тип опирающегося на неё современного консерватизма. Продолжающий линию Льва XIII, Папа Павел VI в энцикликах Populorum progressio, Humane vitae, Ecclesiam suam подчёркивает, что ответственность за другого человека и мир - вместе с борьбой против несправедливости - являются частью евангелизации современных наций. Подобно представляет роль современного католического консерватизма отождествляемого с классическим - Оливейра в написанной в 1959 г. книге - Революция и контрреволюция ${ }^{12}$. Термином революция он обнимает все современные, постоянные стремления к уничтожению христианской цивилизации. Это, с одной стороны атеистические идеологии, разного типа социализмы и коммунизмы, с другой - неолиберализм. Они вводят в жизнь хаос и пессимизм, увеличивают моральное и общественное зло, делают жизнь бессмысленной и безнадежной. Контрреволюция это борьба с ними на фундаменте христианских ценностей, попытка ввести в жизнь современного человека, рождающихся благодаря им, двух ценностей: морального порядка и метафизической надежды. Все современные атеистические идеологии конструируют цивилизацию, которую Папа Иоанн Павел II называл цивилизацией смерти. Её свидетельства имеют разный характер: это не только несправедливые войны, превентивные войны, разного типа террор - милитарный, политический, экономический, культурный - это также аборт, эвтаназия, разрушение семьи, порнография, партнёрские, внебрачные связи, однополые союзы. Католические консерваторы выступают против них, эащишая человеческую жизнь и человеческое достоинство.

Вслед за католическим социальным учением они подчёркивают, что семья является первичной и основной ячейкой общества, а человек общественным существом. Семьи вместе образуют сообщество, сообщество формируется постоянно. Факт, что эти общины умеют самоорганизоваться политически, экономически и социально имеет первостепенное значение. Они свидетельствуют о влиянии на жизнь человеческого достоинства. Католическая Церковь поддерживает частную собственность, однако подчеркивает, что право на собственность не является обязательным.

Рынок не может играть роли безусловного принципа правящего всей жизнью. Классический консерватизм, ссылаясь на принципы христианской этики, защищает человека и общество перед подчинением их «рыночной эффективности» и скомпрометированной уже т.н. волшебной руки рынка. Католическая доктрина говорит не только о достоинстве человека, но и о достоинстве труда

1213 P. Corrêa de Oliveira, Rewolucja i kontrrewolucja, tłum. S. Olejniczak, Kraków 2012. 
и трудовых прав. В энциклике Laborem exercens Папа Иоанн Павел II подчёркивает, что общество должно стремится к экономической справедливости, а экономика должна служить людям, не наоборот. Трудящиеся имеют право зарабатывать деньги на содержание, а также создавать профсоюзы для защиты своих интересов. В профсоюузах, критикуемых, а даже отрицаемых неолиберализмом, проявляется не только солидарность сотрудников, но и христианская добродетель. Католическая доктрина говорит даже о посредничестве государства между руководством предприятий и сотрудниками, вводя понятие его (государства) субсидиарности (доплонительности). Идентичен подход к этим проблемам РПЦ и русского современного консерватизма. Это сходство является не только этической, но и общественной гарантией польско-российского диалога.

Диалог стимулирует тенденцию сближения и одновременно выражает онтологическую и аксиологичческую установку на доминирование человека над средствами общения. Будучи прежде всего формой коммуникации, диалог яввляется вербально зафиксированной перспективой взаимопонимания - самой важной в политике. В этой последней он играет дополнительную роль: организации мирного сосуществования. Такова роль возможна именно на фундаменте христианских ценностей. В их контексте диалог является условием подлинных отношений между человеком и человеком. В этой перспективе обнаруживается исключительная роль диалога как инструмента в борьбе с атомизацией общества, отчуждением человека и его деградацией в массовом обществе, а также т.н. обществе спектакля.

В политике так понимаемый диалог является с одной стороны дополнительной формой реализации международного праыва, с другой - способом обогащения как отдельной личности, так и общества. Это формат не только политического существования, но и взаимного познания, а также взаимопонимания.

Связь диалога как формы общения, коммуникации и познания с христианскими ценностями подтвердила христианская философия диалога Габриэля Марселя, Мориса Недонселя, польского философа Йосифа Тишнера. Диалогическое отношение, или отношение $я-m b l$, мыслится при этом как фундаментальная характеристика положения человека в разных сферах жизни. Всякое существование - это существование по отношению к кому-то и к чему-то. Именно этот атрибут диалога имеет самое важное значение в политике, где он показывает как помочь людям решать конфликты и важные проблемы, учит глубокому пониманию спорных вопросов. Диалог это принятие решений путём взаимопонимания. Он опровергает стереотипы, опирается на доверие, ведет к уважению и гармонии в отношениях. Равноправный, основанный на христианских ценностях диалог позваляет расссматривать его участников с точки зрения их личного достоинства и, одновременно, справедливости. Не допускает в решении вопросов аргументов силы и власти. На эти аспекты диалога и на реализуемые, 
благодаря ему, христианские ценности указывает Совместное послание народам Польши и России подписанное 17 августа 2012 года представителем Польской епископской конференции митрополитом Юзефом Михаликом и патриархом Московским и всея Руси Кириллом.

Обусловленный христианскими ценностями диалог это цивилизационное достижение, которое в настоящее время является наилучшим способом решения трудных внутренних и международных вопросов. Отказ от диалога означает не только переход от: прерсонализма к антиперсонализму, равенства к неравенству, справедливости к несправедливости, общего добра к эгоизму и партикуляризму, солидаризма к отчуждению, эмпатии к ненависти. На культурном уровне он означает возврат к язычеству и соответствующих ему форм поведения, от которых только один шаг к варварству.

Существование христианской цивилизации немыслимо без поддержки общества и государства. В настоящее время сила этой поддержки зависит от силы религиозно-этического консерватизма. Однако, для политических консерваторов государство не может получить значения сакрального фетиша, потому что цель государства состоит не в том, чтобы построить рай на земле, но чтобы земная жизнь не превратилась в ад на земле.

Самую важную роль для будущего христианской цивилизации и самого христианства играют попытки католической и православной Церквей преодолеть разъединенность на пути экуменического диалога. Раскол христиан явление абсолютно противоестественное. Противники экуменизма подчеркивают невозможность построения единства в многообразии. Сторонники диалога усматривают в многообразии богатство христианства, о котором говорит Иоанн Павел II в энциклике Ut unum sint. Взгляды этих последних усиливают позиции христиан в борьбе за христианскую цивилизацию. От укрепления их позиции зависит будущее Европы.

\section{Библиография}

Koneczny F, O lad w historii, Kraków 2003.

Dawson C., Religia i kultura, thum. J. W. Zielińska, Warszawa 1959.

Kaźmierczak P., Dietrich von Hildebrand wobec narodowego socjalizmu, Kraków 2011.

Krąpiec M., Człowiek jako osoba, Lublin 2005, c. 114-145.

Mattei de R., La dittatura del relativismo, Rzym 2003 ; пер.на польский язык: R. De Mattei, Dyktatura relatywizmu, Kraków 2009.

Skudrzyk P., Losy cywilizacji wedlug Arnolda Toynbeego, Katowice 1992.

W. Stróżewski, Istnienie i wartość, Kraków 1981.

Ślipko T., Zarys etyki ogólnej, Kraków 2004.

Тойнбии А., Постижение истории, пер. Е. Д. Жаркова, Москва 2001. 